\title{
Transformações na Atenção à Saúde Indigena: Tensões e Negociações em um Contexto Indigena Brasileiro ${ }^{1}$
}

\author{
Eliana E. Dieh1 ${ }^{2}$
}

Universidade Federal de Santa Catarina, Florianópolis, Brasil ${ }^{3}$ elianadiehl@hotmail.com

\section{Esther Jean Langdon ${ }^{4}$}

Universidade Federal de Santa Catarina, Florianópolis, Brasil ${ }^{5}$ estherjeanbr@gmail.com

\author{
Recibido: 05 de febrero de 2014 \\ Aceptado: 19 de junio de 2014 \\ Disponible en línea: 15 de marzo de 2015
}

\footnotetext{
1 Artigo de reflexão, baseado em pesquisas que vêm sendo realizadas pelas autoras desde os anos 1990. Apoios financeiros: Organização Panamericana de Saúde - Programa de Subvenciones para Tesis de Postgrado en Salud Pública 1998; Edital 003/2004 MS/CNPq/SES/FAPESC; Edital 38/2005 MCT-CNPq/MS-SCTIE-DECIT; Estágio Sênior CAPES 10151-12-5 (Eliana Diehl).

2 Doutorado em Saúde Pública pela Escola Nacional de Saúde Pública Sérgio Arouca da Fundação Oswaldo Cruz, Rio de Janeiro

3 Professora Associado. Departamento de Ciências Farmacêuticas, Programa de Pós-Graduação em Assistência Farmacêutica, Florianópolis, Brasil

4 Doutorado em Antropologia pela Tulane University of Louisiana

5 Professora Titular. Departamento de Antropologia, Programa de Pós-Graduação em Antropologia Social, Florianópolis, Brasil. Pesquisadora do CNPq. Coordenadora do Instituto Nacional de Pesquisa Brasil Plural
} 


\title{
Transformações na Atenção à Saúde Indigena: Tensões e Negociações em um Contexto Indigena Brasileiro
}

\section{Resumo}

Em países da América Latina, programas e políticas públicas voltadas à saúde indígena têm repercutido em novos papéis e espaços de fronteira. Abordando a participação indigena na atenção primária à saúde, analisamos as tensões e negociações antes e após a implantação do Subsistema de Atenção à Saúde Indigena no Brasil, trazendo como exemplo uma Terra Indígena Kaingáng (TIK) do sul do país. Anterior à implantação do Subsistema, a definição e execução dos serviços nessa TIK eram caracterizadas pela forte presença de indígenas ligados à liderança indígena política, e pela fraca presença de instituições. A partir de 2000, o Subsistema vem envolvendo diferentes segmentos públicos e privados. Na TIK, o papel de uma organização Kaingáng estava repleto de ambiguidades e paradoxos, pois ao mesmo tempo que era oportunidade para um maior protagonismo nos espaços de negociação criados pelo Estado, estava submetida às prioridades definidas em espaços exteriores ao grupo étnico.

Palavras-chaves: participação social; fronteira; assimetrias de poder; atenção primária à saúde; indios Sul-Americanos

\section{Transformaciones en la Atención a Salud Indigena: Tensiones y Negociaciones en un Contexto Indigena Brasileño}

\section{Resumen}

En los países de América Latina, los programas y politicas públicas dirigidos a la salud indigena han repercutido en nuevos papeles y espacios de frontera. Abordando la participación indigena en la atención primaria a la salud, analizamos las tensiones y negociaciones antes y después de la implantación del Subsistema de Atención a Salud Indígena en Brasil, trayendo como ejemplo una Tierra Indigena Kaingáng (TIK) del sur del país. Anterior a la implantación del Subsistema, la definición y ejecución de los servicios en esta TIK se caracterizaban por la fuerte presencia de indigenas ligados al líder indigena político y por la débil presencia de las instituciones. A partir de 2000, el subsistema empieza a envolver diferentes segmentos públicos y privados. En la TIK, el papel de una organización Kaingáng estaba repleto de ambigüedades y paradojas, pues al mismo tiempo que era una oportunidad para un mayor protagonismo en los espacios de negociación creados por el Estado, estaba sometido a las prioridades definidas en espacios exteriores al grupo étnico.

Palabras clave: participación social; frontera; asimetrías de poder; atención primaria a la salud; indios Sur-Americanos

\section{Transformations in the Indigenous Health Care: Tensions and Negotiations in a Brazilian Indigenous Context}

\begin{abstract}
In Latin America countries, programs and public policies aimed at indigenous health have impacted on new roles and border spaces. By addressing indigenous participation in primary healthcare, we analyze the tensions and negotiations before and after the implementation of the Indigenous Healthcare Subsystem in Brazil, providing as an example the indigenous land Kaingang (TIK) located in the south of the country. Prior to the implementation of the Subsystem, the definition and execution of the services in this TIK were characterized by the strong presence of indigenous people linked to the indigenous political leader and the weak presence of institutions. Since 2000 , the subsystem started covering various public and private segments. In the TIK, the role of a Kaingáng organization was full of ambiguities and paradoxes, because while it was an opportunity for getting a greater role in the negotiation spaces created by the State, it was also subject to the priorities defined in outer spaces to the ethnic group. Keywords: social participation; border; asymmetries of power; primary healthcare; SouthAmerican Indians
\end{abstract}




\section{Introdução}

Com a implantação do Subsistema de Atenção à Saúde Indígena no Brasil a partir de 2000, novas fronteiras de ação e comunicação foram criadas pelo Estado Brasileiro, visando a inclusão dos povos indígenas no planejamento, gestão, execução e avaliação dos programas e ações de saúde nas Terras Indígenas. Até a reforma constitucional em 1988, a política nacional vigente objetivava a integração dos povos indígenas na sociedade brasileira e as ações esporádicas de saúde tratavam eles como sujeitos passivos e submissos. A nova Constituição garantiu aos povos indígenas acesso universal aos serviços de saúde, atenção à saúde que respeite suas especificidades culturais e práticas tradicionais e participação. Para garantir estes direitos frente à diversidade cultural indigena, o Subsistema foi estabelecido sob a bandeira da 'atenção diferenciada', ou seja, a provisão de serviços de saúde através de uma estrutura separada porém parte integrante do Sistema Único de Saúde (SUS), que articulam com, ou incorporam, as práticas tradicionais das comunidades. Vários espaços de participação foram criados para as organizações e comunidades indígenas nos níveis nacional, regionais e locais. Porém, ao institucionalizar esses espaços com base em pressupostos democráticos que diferem dos modos indígenas de organização social e política ${ }^{6}$ (Garnelo e Sampaio, 2003), ainda não está claro qual é a dimensão do exercício pleno e autônomo dos povos indígenas na garantia de seus direitos, particularmente no nível local onde as comunidades devem contribuir ativamente para o planejamento, execução e avaliação dos serviços de saúde.

Nesse texto, analisamos os conflitos, tensões e negociações sob uma perspectiva da participação indígena no contexto local onde são executadas as ações e serviços da atenção primária à saúde ${ }^{7}$. Tomamos como exemplo a experiência de uma Terra Indigena Kaingáng (TIK) no sul do Brasil antes e depois da implantação do Subsistema. Nosso grupo de pesquisa vem acompanhando os desdobramentos da política de saúde para a realização da atenção diferenciada nos serviços desta TIK

6 No Censo 2010 no Brasil, em torno de 897.000 pessoas se autodeclararam indígenas, fazendo parte de 305 etnias (IBGE, 2010a).

7 No Brasil, a atenção primária à saúde é formalmente denominada 'atenção básica à saúde' pelo Ministério da Saúde. 
desde meados dos anos 1990 sob variadas temáticas, incuindo o papel 'intercultural' dos agentes indigenas de saúde (Langdon et al., 2006; Diehl et al., 2012), medicamentos e práticas de autoatenção (Diehl, 2001; Diehl e Rech, 2004; Ghiggi Jr. e Langdon, 2013) e espaços de controle social ${ }^{8}$ (Langdon e Diehl, 2007). Os muitos anos de pesquisa com este grupo nos permite realizar uma análise comparativa das fronteiras de relações interétnicas do período imediatamente anterior à implantação do Subsistema com aquelas criadas posteriormente à implantação desse modelo, objetivando analisar as formas de protagonismo indígena. No período anterior (anos 1990), as relações tradicionais de poder indígena interferiam na execução dos serviços de saúde no posto de saúde. No segundo, uma recém fundada organização indígena passou a contratar os profissionais de saúde na TIK como consequência de novas fronteiras de participação abertas pelo Subsistema. Não estamos desconsiderando a presença de aspectos de continuidade entre os dois periodos, porém enfatizamos que a participação e autonomia dos Kaingáng diferenciam significativamente entre ambos e nos possibilita avaliar as formas de interação no novo espaço fronteiriço criado pela Política Nacional de Atenção à Saúde dos Povos Indígenas (Brasil, 2002). Permeando a discussão, utilizaremos as noções de participação social em saúde e de espaços de fronteira. A participação social em saúde é aqui entendida como o mecanismo pelo qual grupos organizados intervêm na "formulação, execução e avaliação das políticas públicas para o setor saúde" (Machado, 1986, p. 299). A escolha por este sentido não ignora as ambiguidades observadas no campo das práticas em saúde, bem como outras formas de participação que não implicam grupos organizados formalmente, como apontaremos abaixo. O conceito de espaço de fronteira não é uma referência geográfica, mas um campo relacional comunicativo que busca "dar conta ao mesmo tempo da natureza construída a partir desta zona de contato, assim como da fluidez e do caráter constituinte das relações que se desenvolvem entre os diferentes agentes sociais em contato" (Boccara, 2007, p. 60).

Como em outros países da América Latina nas últimas décadas, a questão da saúde indígena no Brasil tem originado diferentes arenas

8 Controle social é um conceito-chave na idealização do Sistema Único de Saúde no Brasil, que refere à atuação da sociedade civil "na gestão das políticas públicas no sentido de controlá-las para que atendam às demandas e aos interesses da coletividade" (Correia, 2000, p.11). 
de interlocução e embates, em variados níveis (do local ao internacional), envolvendo uma diversidade de atores (indígenas, gestores, profissionais de saúde, prestadores de serviços, missionários, agentes para-estatais, pesquisadores, etc.). Em cada espaço "imperam mecanismos performativos de denominação e rituais de tomada de posse que levam à formação de novos sujeitos sociais" (Boccara, 2007, p. 60), bem como desenvolvem estratégias que (re)definem suas identidades indígenas e que reforçam seus direitos. Esses espaços, ao mesmo tempo, demonstram o quão paradoxal é o processo, já que a etnicidade indígena passa a fazer parte do discurso dos estados neoliberais e das politicas públicas, que em termos gerais essencializam a noção de cultura e despolitizam os processos de participação comunitária. Pretendemos aqui examinar o potencial e as contradições da participação das Organizações Não Governamentais (ONGs) indígenas na execução dos serviços de saúde com base no exemplo citado.

Os dados que permitiram realizar essa reflexão foram obtidos entre os anos de 1994 e 2012 nessa TIK, quando foram desenvolvidas pesquisas etnográficas através de observação participante, entrevistas semi-estruturadas, grupos fociais e análise documental, envolvendo diferentes temáticas, como antropologia dos medicamentos, papel de profissionais indígenas de saúde (agentes indígenas e técnicos de enfermagem) e práticas de autoatenção à saúde. Todas as pesquisas foram submetidas a um Comitê de Ética e à Comissão Nacional de Ética em Pesquisa (CONEP), bem como à Fundação Nacional do Índio, e nesse artigo, por questões de preservar o anonimato dos indigenas (ou dos pesquisados), optou-se por designar gerericamente a Terra Indígena como sendo Kaingáng e não nomear os municípios onde essa Terra está localizada.

\section{O desenvolvimento da Politica de Saúde Indigena}

Os órgãos tutelares oficiais (o Serviço de Proteção aos Índios, que funcionou de 1910 até meados da década de 1960, e a Fundação Nacional do Índio/FUNAI, responsável a partir de 1967), apesar de apresentarem entre suas responsabilidades a saúde indígena, não 
implementaram políticas e ações realmente efetivas ou adequadas de assistência. Ao contrário, a política de integração e as frentes de colonização foram muito mais eficazes em provocar uma ruptura social, cultural, ecológica e sanitária dos povos indígenas contatados.

Nos anos 1980 e boa parte da década de 1990, o tema da saúde tornou-se emblemático como parte dos movimentos de redemocratização do Brasil. De um lado, as Conferências de Saúde definiram a importância da participação da sociedade civil nas instâncias de controle social em todos os seus niveis e de outro os governos trataram de estabelecer legislações que nem sempre avançavam nessa direção, como foi o caso da saúde indígena. Durante essas duas décadas não foram criadas maneiras efetivas para a participação das comunidades indígenas nos serviços locais.

Em 1986, a I Conferência Nacional de Proteção à Saúde do Índio discutiu e deliberou sobre políticas de saúde frente à municipilização proposta como base do SUS. Passaram então a ser centrais as discussões em torno da implementação de um modelo diferenciado para a saúde indígena, baseado no respeito à organização social e política, aos costumes e às tradições dos diversos povos indígenas, preceitos que acabaram sendo contemplados na Constituição Brasileira de 1988. Em 1993, foi realizada a II Conferência Nacional de Saúde Indígena, como parte integrante da IX Conferência Nacional de Saúde, convocada pelo Ministério da Saúde. Os delegados indígenas, constituindo 50\% do total presente, foram eleitos no processo de Conferências estaduais e regionais, segundo os critérios populacionais de concentração dos povos indígenas no país, nas suas diferentes regiões ${ }^{9}$. Várias resoluções resultaram dessa Conferência, entre elas a criação de distritos sanitários.

Apesar das Conferências, não houve na década de 1990 uma política de saúde adequada que definisse ações e serviços para os povos indigenas. A responsabilidade pela saúde indigena flutuou entre a FUNAI e a Fundação Nacional de Saúde (FUNASA), sem recursos adequados e contando com algumas missões religiosas e universida-

9 O Brasil possui cinco regiões: sul, sudeste, nordeste, centro-oeste e norte. Essas regiões concentram uma grande diversidade de etnias e no sul podemos citar a presença de Kaingáng, Xokleng e Guarani. 
des para a prestação de cuidados de saúde às comunidades indígenas específicas. Em 1991, o Decreto n. 23 (Brasil, 1991) criou a figura dos 'distritos sanitários de natureza especial', responsáveis pela operacionalização de "projetos específicos, de caráter estratégico, destinados à promoção, proteção e recuperação da saúde do índio, segundo as peculiaridades de cada comunidade" (Brasil, 1991, p. 2486), mantendo a prestação individualizada de assistência médica pela rede de serviços do SUS. O único Distrito Sanitário criado em 1991 foi o Yanomami ${ }^{10}$, que segundo Magalhães (2001) enfentrou as mais diversas dificuldades para sua condução durante os anos 1990, chamando a atenção para a participação quase nula dos indígenas.

Os debates sobre o modelo de atenção à saúde indígena continuou durante toda a década, mas sem uma clara definição. Questões mal resolvidas quanto ao âmbito de competência das instituições envolvidas provocaram uma desarticulação nas ações para a saúde indígena. Além disso, a falta de recursos financeiros adequados por parte do Estado brasileiro ocasionou grandes problemas para a execução da atenção à saúde indígena que garantisse acesso universal e serviços adequados.

Visando estabelecer instâncias de participação e controle social, em 1991 foi criada a Comissão Intersetorial de Saúde do Índio (CISI), vinculada ao Conselho Nacional de Saúde (CNS). O papel da CISI, desde a sua criação, é assessorar ou subsidiar o CNS na formulação e no acompanhamento de políticas públicas de saúde indígena. Dos 11 membros originais, quatro eram representantes de organizações indígenas ${ }^{11}$ (Castellani, 2012). Durante a década, a Comissão apoiou o projeto de lei propondo o estabelecimento dos Distritos Sanitários Especiais Indigenas. Desde 1993, houve tentativas de criar conselhos locais e regionais de saúde para garantir maior participação indígena, porém a

\footnotetext{
${ }^{10}$ O Distrito Sanitário Yanomami foi a primeira experiência de organização dos serviços de saúde para os Yanomami segundo os preceitos da reforma sanitária e da I Conferência Nacional de Proteção à Saúde do Índio. Em que pesem as inúmeras dificuldades enfrentadas pelo referido Distrito entre 1991 e 1998, Magalhães (2001) salienta que essa experiêndia, juntamente com os movimentos sanitário e sanitário-indigenista, culminou na "ampla reformulação da prática sanitária direcionada aos povos indigenas” (p. 121), referindo-se à criação do Subsistema de Atenção à Saúde Indígena em 1999.

11 Coordenação das Organizações Indígenas da Amazônica Brasileira (COIAB), Conselho Indígena de Roraima (CIR), Articulação dos Povos Indígenas do Nordeste, Minas Gerais e Espírito Santo (APOINME) e União das Nações Indigenas do Acre (UNI-AC).
} 
implantação desses conselhos enfrentava vários problemas, e até o final da década poucos foram efetivamente estabelecidos.

Finalmente, em 1999 foi aprovado o Subsistema de Atenção à Saúde Indígena (Brasil, 1999a) com base nos Distritos Sanitários Especiais Indígenas (DSEIs) (Brasil, 1999b). Além dos princípios do SUS de universalidade, equidade, integralidade, participação comunitária e controle social, inclui o princípio da atenção diferenciada. Idealmente, esse princípio deve permear todas as diretrizes da Política Nacional de Atenção à Saúde dos Povos Indígenas (PNASPI), sendo uma de suas definições "o respeito às concepções, valores e práticas relativos ao processo saúde-doença próprios a cada sociedade indígena e a seus diversos especialistas" (Brasil, 2002, p. 18). É importante salientar que, diferentemente dos anos anteriores, o governo federal destinou em torno de 96 milhões de dólares ${ }^{12}$ à montagem dos DSEI em 1999 (Garnelo, 2012), aumentando esses recursos gradativamente até o valor aproximado de 426 milhões de dólares ${ }^{13}$ em 2013 (Portal Brasil, 2014).

O modelo foi organizado por meio de uma estrutura baseada em 34 DSEIs, que devem oferecer a atenção primária à saúde nas Terras Indigenas com equipes multidisciplinares de saúde indígena (EMSI) compostas basicamente de médicos, dentistas, enfermeiros, auxiliares e técnicos de enfermagem, agentes indígenas de saúde e agentes indígenas de saneamento; os serviços especializados e hospitalares devem ser os mesmos da rede SUS que atende a população brasileira em geral. Um sistema de Conselhos Locais e Distritais foi criado visando garantir a participação indígena no planejamento e avaliação dos serviços e uma vaga para indígena foi aberta no Conselho Nacional de Saúde; na CISI, a partir de 2006, um indigena assumiu a coordenação, aumentando o número de seus representantes nessa Comissão. Ainda mais, o papel do agente indígena de saúde foi institucionalizado, definindo-o como o elo entre os saberes indígenas e biomédicos e entre a equipe de saúde e os membros das comunidades por ela atendidos.

\footnotetext{
12 Aproximadamente $\mathrm{R} \$ 180$ milhões, convertidos pela média do dólar no período dos últimos seis meses de 1999.

${ }^{13}$ Em torno de R\$ 1 bilhão (média do dólar no mês de dezembro de 2013).
} 
Até 2011, a FUNASA era o órgão encarregado pela coordenação, normatização e execução das ações, sendo substituída então pela Secretaria Especial de Saúde Indígena (SESAI). Porém, desde o início do Subsistema, os serviços de saúde nas Terras Indigenas têm sido executados através de convênios com municípios e/ou ONGs, caracterizando a terceirização do Subsistema (Garnelo e Sampaio, 2003). O papel dos municípios tem sido um ponto de conflito e de debates. Desde a I Conferência em 1986, os povos indígenas reivindicaram a criação de uma Secretaria junto ao Ministério da Saúde para coordenar as ações de saúde indígena, ou seja, propunha-se a gestão e execução pelo nível central nacional, e não pelos municípios. Uma vez implantado o Subsistema, municípios firmaram convênios com a FUNASA nos locais onde não existia uma ONG que se responsabilizasse pela atenção primária nas Terras Indígenas. Em alguns casos, organizações indigenas assinaram convênios, dando a elas, a princípio, o papel central no planejamento, gestão e execução da atenção primária via a contratação de equipes de saúde. Como veremos no caso examinado aqui, a ONG dos Kaingáng foi criada especificamente para assumir ações em saúde, educação e em outros programas. As primeiras ONGs indígenas a participarem do Subsistema foram aquelas que se consolidaram durante a década de 1990 na luta pela terra, saúde e educação. A participação das ONGs indígenas como conveniadas foi percebida pelas lideranças indígenas como uma nova oportunidade para o protagonismo e autodeterminação.

\section{A gestão e execução dos serviços de saúde na Terra Indigena Kaingang (TIK)}

Os Kaingáng vivem nos estados do Rio Grande do Sul, Santa Catarina, Paraná e São Paulo, constituindo uma das maiores populações indígenas do Brasil, em constante e permanente contato com a sociedade não indígena. Pertencem ao tronco linguístico Macro-Jê, à semelhança de outros grupos da região central do Brasil, como os Xávante e os Kayapó. A TIK está localizada em dois pequenos municípios de Santa Catarina e tem 11 aldeias distribuídas em torno de 15.600 hectares, rodeadas de grandes fazendas de propriedade de não indígenas, com monocultura de soja e 
milho, duas das principais economias do Estado. No Censo Demográfico de 2010 (IBGE, 2010b), na TIK declararam-se indígenas 3.935 indivíduos, sendo a maior parte de Kaingáng e em menor proporção Guarani e Xetá. Esse número tem se mantido mais ou menos estável nas últimas duas décadas, em que pesem as divergências dependendo da fonte de informação. É importante ressaltar que os Kaingáng não manifestam os sinais diacríticos associados com a identidade indígena no Brasil, tais como marcas e adornos no corpo, uso cotidiano da língua, rituais performativos, etc. Isto reflete diretamente na conduta das equipes de saúde que não percebem que há uma diferenciação em relação à sociedade envolvente e, consequentemente, não veem como necessários serviços e ações culturalmente adequados.

\section{Os anos 1990}

A disponibilidade dos serviços de saúde oferecidos na TIK foi caracterizada até meados de 1998 pela intermitência. Existia uma enfermaria, como à época era chamado o posto de saúde, na maior aldeia da TIK. Eventualmente, patrocinadas pela FUNAI, equipes volantes de saúde, compostas basicamente por médicos, dentistas e enfermeiros, visitavam as diversas aldeias, visando à vacinação, diagnóstico inicial, distribuição de medicamentos e assistência odontológica. Nos anos de 1994 e 1995 não eram oferecidos serviços sistemáticos de profissionais de nivel superior na enfermaria, contando somente com a presença dos atendentes de enfermagem da FUNAI. No ano de 1996, havia um dentista duas vezes por semana na maior aldeia, cedido por um dos municípios (aqui identificado como X) conveniado com a FUNAI.

Em agosto de 1998, o dentista mantinha as atividades e um médico, contratado pelo convênio FUNAI-município X, prestava atendimento uma vez por semana na maior aldeia. Além disso, o convênio FUNAI-município X e outro convênio FUNAI-ONG não indigena (aqui denominada A) proporcionaram a contratação de auxiliares de enfermagem (alguns indígenas) e agentes indígenas de saúde. 
Em julho de 1999, com a implantação do Programa de Saúde da Família $(\mathrm{PSF})^{14}$ para a área indígena, o município $\mathrm{X}$ criou uma equipe com seis agentes indígenas de saúde e profissionais não indígenas (uma auxiliar de enfermagem, uma enfermeira e um médico). Em novembro de 1999, o outro município (aqui chamado de Y) da TIK também montou uma equipe, composta de sete agentes indigenas de saúde e outros profissionais não indígenas (uma auxiliar de enfermagem, uma enfermeira e um médico).

Na segunda metade de 1999, o posto de saúde localizado no município $\mathrm{X}$ foi a referência para a busca de atenção biomédica quando não se resolvia o problema na enfermaria. Porém, como a maioria dos pequenos municípios rurais, a carência de infraestrutura adequada para atender a população levava quase sempre o encaminhamento dos casos, muitas vezes de simples resolução, para municípios maiores da região.

\section{Os anos 2000}

Na TIK, a partir de janeiro de 2000, houve um rearranjo do quadro funcional em função da instalação do DSEI Interior Sul, com dispensa de alguns profissionais e realocação e contratação de outros por meio de novos convênios: 2000 a novembro de 2003 FUNASA-município X; entre dezembro de 2003 e agosto de 2008 FUNASA-ONG indígena; setembro de 2008 a 2011 FUNASA-ONG não indígena B; entre 2012 e 2013 SESAI-ONG não indígena C. Foram criadas duas equipes multidisciplinares de saúde indígena (EMSI A e B) ${ }^{15}$, uma para cada conjunto de aldeias dos dois municípios, e de 2000 a 2011 o número de profissionais variou entre 31 e 34 na EMSI A e entre 10 e 15 na EMSI B. Um dos principais problemas enfrentados pelas EMSI era a alta rotatividade, especialmente de médicos e agentes indigenas de saúde

\footnotetext{
${ }^{4}$ A Saúde da Familia é uma estratégia de reorientação do modelo assistencial, operacionalizada mediante a implantação de equipes multiprofissionais em unidades básicas de saúde. As equipes devem atuar por meio de ações de promoção da saúde, prevenção, recuperação, reabilitação de doenças e agravos mais frequentes, e na manutenção da saúde das comunidades atendidas. (Disponivel em: http:// portal.saude.gov.br/portal/saude/cidadao/area.cfm?id_area=149. Acesso em: 30 maio 2013).

15 Compostas por médico, dentista, enfermeiro, auxiliar/técnico de enfermagem, auxiliar de consultório dentário, agente indígena de saúde e agente indígena de saneamento (mais tarde foi incorporado nutricionista na EMSI A). Ainda por períodos curtos, fizeram parte também assistente social e psicóloga na EMSI A.
} 
(em menor proporção enfermeiros e dentistas), situação semelhante aos demais Distritos Sanitários no país. Outros dois problemas vividos pelas duas EMSI eram a precarização dos vínculos trabalhistas, com salários muito díspares entre as várias categorias profissionais que compõem a equipe, e a pouca e descontínua capacitação dos trabalhadores, impactando na alta rotatividade.

Na porção localizada no município $X$ que tem a maior parte da TIK, existem três postos de saúde, sendo que dois deles mantinham uma regularidade nos serviços de saúde, contando com toda a EMSI A, e o terceiro tinha o apoio cotidiano de um agente de saúde e de um técnico indígena em enfermagem. A área em território do outro município tem dois postos de saúde, mantidos regularmente por agentes indígenas de saúde e de saneamento, auxiliar de consultório dentário e auxiliares/técnicos de enfermagem e com certa frequência por médico, dentista e enfermeiro (EMSI B).

\section{Os contextos locais e os novos espaços de fronteira}

Apesar da falta de regularidade de serviços médicos antes da implantação do Subsistema, a enfermaria do final dos anos 1990 era uma arena social onde os trabalhadores indígenas ou aqueles indígenas diretamente ligados às lideranças exerciam poder nas relações com os profissionais. A atendente de enfermagem e coordenadora local da enfermaria, servidora da FUNAI e esposa de um ex-cacique (cuja família continuava exercendo cargos de chefia na TIK), dispunha de autoridade para tomar decisões, inclusive ignorando as prerrogativas colocadas pelos médicos e outros funcionários. Era ela quem controlava todas as compras de medicamentos, solicitava ao médico a prescrição de medicamentos psicotrópicos, marcava e desmarcava exames (algumas vezes ordenou que os médicos requisitassem exames), instruía sobre o uso do carro destinado à saúde. Apesar da existência de critérios para o atendimento médico, lideranças, seus parentes e aliados dificilmente deixavam de ter prioridade na atenção; nesse sentido, a atendente-coordenadora tinha o papel de intermediar, solicitando a consulta. 
Os conflitos eram muito evidentes na questão dos medicamentos, pois se os médicos possuíam autonomia para prescrever, isso não significava que o indígena iria receber exatamente o que foi prescrito. Havia uma avaliação por parte do profissional indígena que entregava os medicamentos, que podia ser referendada na sua própria experiência, em critérios de existência ou não no estoque, ou mesmo na disponibilidade de recursos financeiros para a aquisição no comércio farmacêutico. De igual modo, nos dias em que não tinha médico, a entrega sem prescrição médica continuava sendo feita. Quando atitudes divergentes eram confrontadas, isso não significava que os conselhos médicos passariam a ser ouvidos e cumpridos. Ao contrário, a autonomia dos atendentes e auxiliares de enfermagem era mantida.

Em 1999, os profissionais da enfermaria eram oriundos de diferentes tipos de contrato (diretamente pelo município X e pela FUNAI; convênio FUNAI-município X; convênio FUNAI-ONG não indígena A), o que gerava conflitos e algumas discussões em torno de salários, tarefas e horários a serem cumpridos, bem como a qual instituição se devia obediência. Por exemplo, os atendentes e auxiliares de enfermagem, que permaneciam durante todo o periodo de funcionamento na enfermaria, questionavam o fato de que os médicos e o enfermeiro não estavam todos os dias trabalhando e recebiam salários muito maiores.

A Coordenação Regional (CR) da FUNAI, situada a cerca de $80 \mathrm{Km}$ da TIK, não se fazia presente na enfermaria e eventuais problemas ou dificuldades que não eram resolvidos localmente, eram reportados pela coordenadora, que em geral fazia o percurso até a CR. Esse período, portanto, foi marcado por uma fraca ou inexistente institucionalização e por uma participação indígena que não envolvia uma organização formal e nem instâncias decisórias mais amplas, mas que dependia das forças políticas existentes na organização tradicional do grupo e da ocupação de cargos na enfermaria pela mulher do ex-cacique e por indígenas auxiliares de enfermagem.

Em resumo, o período da década de 1990 na TIK pode ser caracterizado pela forte presença local de indígenas relacionados à liderança política na definição e condução das atividades na enfermaria, já que 
as instituições envolvidas não tinham um papel claro e presente na prestação de serviços. Nesse cenário, a participação estava circunscrita ao grupo diretamente envolvido nas atividades cotidianas de saúde, observando-se que as relações de micropoder levaram a práticas de acesso diferenciado a serviços e medicamentos. No final dos anos 1990, com o acréscimo de profissionais (médico, dentista e enfermeiro) e extensiva distribuição de medicamentos, houve um aumento na presença dos serviços biomédicos, caracterizada cada vez mais por uma estrutura de serviços que não se observava em muitas Terras Indígenas de outras regiões do Brasil.

A partir de 2000, o processo de implantação do Subsistema abriu novas fronteiras de representação e participação social. O Conselho Local de Saúde foi organizado na TIK, e os Kaingáng tornaram-se representantes de suas comunidades tanto em nível local quanto regional (Conselho Distrital de Saúde Indígena Interior Sul).

Central para nossa análise foi a fundação em 2003 de uma ONG Kaingáng como entidade privada sem fins lucrativos, visando substituir o município $\mathrm{X}$ na execução dos serviços de atenção primária à saúde na TIK por meio de convênio com a FUNASA ${ }^{16}$. Esse fato chama a atenção, pois no sul do Brasil não houve uma mobilização intensa para a criação de organizações indígenas para reivindicações políticas, como aconteceu em outras regiões do país no final dos anos 1980 e principalmente na década de 1990, quando mais de 250 ONGs indigenas foram criadas na região amazônica (Albert, 2001), seguindo tendências observadas em outros países da América Latina. A implantação do Subsistema trouxe novas oportunidades para atuação das organizações indígenas. Na Amazônia, entre 1999 e 2004, um total de 26 associações indígenas haviam firmado convênio com a FUNASA para executar ações de saúde nos DSEIs (Garnelo, 2012, p. 47).

16 Durante o período de atuação da ONG (dezembro de 2003 a agosto de 2008), os recursos financeiros envolvidos foram da ordem de U\$ 1,106,000.00 (valor em dolar atualizado para maio de 2013). (Fonte: Portal da Transparência. Disponivel em: http://www.portaltransparencia.gov. $\mathrm{br} /$ convenios / ConveniosListaEstados.asp?TipoConsulta $=0$. 
Segundo um dos presidentes da ONG Kaingáng, desde a implantação do Subsistema em 2000, o município X não prestava um atendimento satisfatório, pois entendia os recursos como sendo do município e não especificamente para a população indígena, o que levou à "necessidade da população indígena ter poder e de forma autônoma começar a andar com as suas próprias pernas" (Presidente da ONG, entrevista em janeiro de 2007). Esse presidente informou que a organização:

[...] foi criada para um propósito maior, questão da agricultura, da educação, habitação. Hoje [referindo-se a 2007] não temos só convênio com a saúde, mas agricultura também, com o estado de Santa Catarina. [...] hoje assessora voluntariamente todas as instituições dentro da área indígena, como clube de mães, projetos. Além de cuidar da saúde, faz trabalho voluntário para ajudar a comunidade. Na época foi criada para poder gerenciar o convênio, tocar num momento da crise.

Conforme seu relato, a FUNASA estimulou a criação da ONG como forma de torná-la modelo de gerência para as demais áreas indígenas.

A ONG possuía uma estrutura organizacional composta por: presidente, vice-presidente, primeiro e segundo secretário, primeiro e segundo tesoureiro, conselho fiscal e assembleia geral; e departamentos de saúde, de educação, de agricultura e de assistência social. O primeiro presidente foi escolhido por aclamação em assembleia de fundadores (lideranças e convidados) e os subsequentes por votação em assembleia de representantes de cada aldeia da TIK. A frase 'Idealizar para superar', lema da organização e observada nas laterais de seus carros, foi segundo o presidente da ONG proposta por ele (entrevista em janeiro de 2007):

$\mathrm{Na}$ verdade [rindo] nós partimos da estaca zero [...] 'Idealizar para superar' é primeiro concretizar mesmo a questão da organização, para depois você superar principalmente a questão do descrédito que a população indígena tem, tinha, e isso nós acreditamos que nós estamos superando, esse descrédito que ao longo do tempo foi pensado para população indígena. A questão 'idealizar para superar' 
está nessa direção. [...] O início do trabalho, para idealizar mesmo, a frase em si já diz tudo.

A ONG indígena procurou diversificar suas ações e buscar maior autonomia na gestão dos recursos financeiros. Porém, essa autonomia foi aparente, já que os recursos para a saúde deviam ser aplicados conforme rubricas pré-definidas pela FUNASA para a execução das ações a cargo das entidades conveniadas. Além disso, o fluxo administrativo-burocrático da coordenação geral no DSEI, localizada em Florianópolis (cerca de $550 \mathrm{Km}$ de distância da TIK), centralizando a gestão, e o não engajamento da FUNASA pouco contribuíram para a organização local dos serviços e o cumprimento pleno dos Planos de Saúde nessa Terra Indígena. Para o presidente da ONG, as mudanças no DSEI Interior Sul, incluindo sua coordenação (no periodo de atuação da organização indígena, houve mais de um coordenador geral do DSEI) e o não repasse dos recursos financeiros segundo os cronogramas previamente definidos no convênio, desarticulavam o trabalho da organização.

$\mathrm{Na}$ execução dos serviços, havia conflitos entre os indígenas da ONG e os gestores do municipio onde se localiza a maior parte da TIK, oriundos principalmente das responsabilidades de cada um e do tipo de contrato dos profissionais (a ONG contratava os de nível superior e técnico e alguns agentes indígenas de saúde, e o município contratava pelo Programa de Saúde da Família um enfermeiro e outro grupo de agentes indígenas de saúde). Em contraposição, no outro município alguns indígenas ocupavam cargos executivos na administração municipal, o que criava uma configuração política mais favorável para a estruturação da saúde indígena e um diálogo com a ONG.

Apesar de um melhor ambiente no município Y, os excessos da estrutura burocrática que se instalou na ONG estabeleceram para a equipe dos postos de saúde um papel de cumpridores de tarefas. A equipe, apesar da sua motivação para o trabalho, tinha dificuldades para aliar as necessidades da comunidade às exigências e recursos disponibilizados pelo convênio FUNASA-ONG. Além desta desarticulação entre as duas partes, a inexistência de uma coordenação local formalizada nos postos de saúde, uma descontinuidade nas condições de tra- 
balho (momentos sem transporte, sem telefone, sem medicamentos e outros insumos) e a alta rotatividade de profissionais de saúde prejudicavam o desenvolvimento continuado das ações, gerando indignação da equipe ${ }^{17}$. Os conflitos, tanto no âmbito das relações inter-institucionais como dentro da equipe, se estenderam até agosto de 2008, quando o convênio foi desfeito. A ONG continuou executando por alguns meses projetos na área da agricultura e educação, porém ficou inativada por um período de dois anos e em 2013 estava buscando parcerias para retomar as atividades.

\section{Comentários finais}

Com a implantação do Subsistema de Atenção à Saúde Indígena, foram criados novos papéis de participação para os indígenas, exercidos em três principais espaços de fronteira de ação e comunicação: agentes indígenas de saúde, conselheiros indígenas nas instâncias de participação e controle social e organizações indígenas como gerentes e executores dos serviços de saúde. Os agentes indígenas de saúde, membros das equipes de saúde, têm o papel importante de servir como mediadores no espaço da atenção primária à saúde. Porém na prática, pesquisas (Langdon et al., no prelo; Pontes et al., 2012) demonstram que seu papel é de um subordinado, não reconhecido como profissional de saúde, sendo um mensageiro sem autonomia nas situações onde existem outros profissionais presentes com uma certa continuidade. O controle social, através da eleição democrática de representantes indígenas, também mostra-se como um processo contraditório, com problemas de representatividade, rotatividade de membros e pouca ou inexistente capacitação. No caso do Conselho Distrital do DSEI Interior Sul, por exemplo, as demandas trazidas pelos representantes indigenas, muitos deles empregados das instituições responsáveis pelas ações e serviços, em geral apresentavam um caráter individualizado e não de interesses coletivos (Langdon e Diehl, 2007).

\footnotetext{
17 A pesquisa realizada entre os agentes indigenas de saúde em 2004/2005 (Langdon et al., 2006) apontou uma grande insatisfação destes na sua relação com os demais membros da EMSI A.
} 
Este artigo enfocou o terceiro espaço de fronteira criado para a atuação dos indígenas com o Estado, ou seja, o espaço do gerenciamento e execução das ações e serviços de saúde pelas ONGs indígenas. No ínicio do Subsistema, os serviços foram terceirizados, e um número de organizações indígenas assinaram convênios com a FUNASA, particularmente entre 2000 e 2004 (Garnelo, 2012). Semelhante a outros países da América Latina (Boccara, 2012), nossas pesquisas e outras no Brasil demonstram que a oportunidade para maior envolvimento dos indígenas no exercício de seus direitos e maior protagonismo nos espaços de negociação criados pelo Estado está repleta de ambiguidades e paradoxos (Albert, 2001; Magalhães, 2001; Garnelo e Sampaio, 2003; 2005; Shankland e Athias, 2007). Por um lado, estes novos espaços foram criados para garantir a participação das comunidades indigenas no planejamento e execução dos serviços de saúde visando respeitar a cultura e formas de organização indígena, podendo ser vistos como mecanismo de reabilitação/reivindicação de identidades e espaço para o exercício do próprio poder (Menéndez, 2010). Por outro, se transformam de organizações militantes em organizações profissionais (Albert, 2001), se convertendo em agentes de reprodução do sistema dominante, cuja atuação é moldada pelas prioridades definidas em espaços exteriores aos grupos étnicos. O aumento de recursos visando atividades assistenciais por essas organizações assumiram prioridade frente à sua atuação como contestadora e revindicadora de direitos.

O potencial de maior protagonismo expresso na fala do presidente da organização Kaingáng sobre as razões de sua fundação ecoa na percepção das lideranças na III Conferência Nacional em Saúde Indigena (2001), quando, discutindo sobre a participação das organizações indígenas na terceirização dos serviços, o indígena Gerson Baniwa se manifestou: "É hora da gente assumir a responsabilidade de nosso futuro. Nós precisamos ser sujeitos compromissados com as soluções dos nossos problemas e não ficar só esperando" (Garnelo e Sampaio, 2005, p. 1221). Entre as vantagens deste protagonismo, vêm sendo apontadas a oportunidade para novas aprendizagens de racionalidades tecnoburocráticas, a maior autodeterminação e a superação do estigma de incapacidade instituído pelo regime tulelar. 
Porém, como nossas pesquisas demonstram aqui, o potencial desta atuação não se realizou plenamente, devido a uma sequência de contradições observada neste espaço de negociação entre o Estado e os indígenas. As formas organizacionais e posições indígenas misturaram, e as organizações enfrentaram duplas demandas da FUNASA e da comunidade. As comunidades atribuíram a elas o ônus dos problemas de atrasos em recursos financeiros e nas contratações de profissionais de saúde, de falta de medicamentos e de outras interrupções nos serviços de saúde, que eram em realidade causados pela FUNASA. Simultaneamente, as relações conveniais determinaram o ritmo de trabalho, forçando a organização indígena ao cumprimento de programações, metas, prazos e orçamentos definidos externamente.

A partir de 2004 houve uma reversão da política com as conveniadas, havendo uma maior centralização na sede da FUNASA em Brasilia e vários recursos e responsabilidades foram retirados das organizações indígenas (Garnelo, 2012). Instalou-se uma política favorecendo o aumento do papel dos municípios na execução dos serviços e a redução dos convênios com as ONGs indígenas. Por exemplo, em 2006, a Federação das Organizações Indígenas do Rio Negro (FOIRN), conveniada desde 2002, encerrou o convênio em protesto pela perda de sua autonomia na execução das ações de saúde (FOIRN, 2006). Cabe lembrar que a ONG Kaingáng foi criada durante esta transição, e sua perda de autonomia na condução das rotinas reflete o aumento de centralização pela FUNASA.

Os governos dos países da América Latina têm estabelecido estratégias diversas nas políticas de saúde para garantir aos indígenas acesso aos serviços, definindo estes como espaços de interculturalidade, ou seja, espaços de encontro de tradições de culturas diferentes. Como argumentado por Boccara para o Chile (2012), o campo da interculturalidade perdeu seu potencial para a crítica devido à sua apropriação pelo Estado. O potencial político, como parte das reivindicações das organizações indígenas militantes, também se perdeu e os indígenas sofreram uma perda de autonomia e autodeterminação, como vimos no caso do Brasil sobre as limitações de atuação impostas às ONGs indígenas na execução e planejamento dos serviços. Esta 
observação soma-se a outras sobre os aspectos mais qualitativos referentes à qualidade e interculturalidade nas relações dos serviços de saúde. Apesar de documentos internacionais e nacionais estabelecerem a necessidade de um atendimento em saúde orientado para as especificidades culturais, incluindo o respeito e a articulação com as práticas e conhecimentos indígenas, análises de projetos em medicina tradicional demostram mais uma vez um espaço paradoxal de fronteiras étnicas (Follér, 2004; Ferreira, 2013; Langdon, 2013).

Mais de uma década após a implantação do Subsistema, os contextos politicos e de gestão refletem em uma organização local que compromete as relações de trabalho e a dinâmica de prestação de serviços. A execução das ações e serviços de saúde e a participação social, seguindo práticas desarticuladas com as realidades locais, impõem obstáculos à viabilização das diretrizes básicas do Subsistema. É necessário considerar que as especificidades sociais, politicas e culturais são fundamentais para entender que os projetos e programas políticos-culturais dos estados multiculturais, como são os países da América Latina, estão sempre em construção, justapondo e tensionando diferentes visões repletas de contradições, se desenvolvendo por meio de "novas lutas de poder e de classificações entre os novos agentes sociais estatais ou paraestatais" (Boccara, 2012, p. 2), produzindo espaços de etnização e reificação da cultura (Boccara, 2007). Como apontado por analistas do processo de indigenismo em países da América Latina, as assimetrias de poder entre os povos indígenas e estados nacionais continuam nas ideologias e praxis das políticas indigenistas (Silva, 2012, p. 28).

\section{Referências}

Albert, B. (2001). Associações indígenas e desenvolvimento sustentável na Amazônia brasileira. Em Ricardo (Org.) Povos Indigenas no Brasil, 1996-2000 (pp. 197-203). São Paulo: ISA.

Boccara, G. (2007). Poder colonial e etnicidade no Chile: territorialização e reestruturação entre os Mapuche da época colonial. Revista Tempo 23, 56-72. 
Boccara, G. (2012). La interculturalidad en Chile: entre culturalismo y despolitización. Em $28^{a}$ Reunião Brasileira de Antropologia. São Paulo, 2 a 5 de julho de 2012, São Paulo.

Brasil (1991, 05 de fevereiro). Decreto n. 23, de 04 de fevereiro de 1991. Diário Oficial da União, Seção 1, pp. 2486. Disponivel em: http://pesquisa.in.gov. $\mathrm{br} /$ imprensa/jsp/visualiza/index.jsp?jornal=1\&pagina=2\&data=05/02/ 1991 .

Brasil (1999a). Lei n. 9.836 de 23 de setembro de 1999. Disponivel em: http:/ / www.planalto.gov.br. Acesso em: 11 julho 2000.

Brasil (1999b, 28 de agosto). Decreto n. 3.156 de 27 de agosto de 1999. Diário Oficial da União. Edição Extra, n. 165-A, Seção 1, pp. 37-38.

Brasil (2002). Fundação Nacional de Saúde. Politica Nacional de Atenção à Saúde dos Povos Indigenas. Brasília: Ministério da Saúde/Fundação Nacional de Saúde.

Castellani, M. R. (2012). Subsistema de saúde indígena: alternativa bioética de respeito às diferenças. Dissertação de Mestrado (Bioética). Brasília, Universidade de Brasília.

Correia, M. V. C. (2000). Que Controle Social - os conselhos de saúde como instrumento. Rio de Janeiro: Fiocruz.

Diehl, E. E. (2001). Entendimentos, Práticas e Contextos Sociopolíticos do Uso de Medicamentos entre os Kaingáng (Terra Indígena Xapecó, Santa Catarina, Brasil). Tese de Doutorado (Saúde Pública). Rio de Janeiro, Escola Nacional de Saúde Pública, Fundação Oswaldo Cruz.

Diehl, E. E. e Rech, N. (2004). Subsídios para uma assistência farmacêutica no contexto da atenção à saúde indígena: contribuições da antropologia. Em Langdon e Garnelo (Orgs.) Saúde dos Povos Indígenas - reflexões sobre a antropologia participativa (pp. 149-169). Rio de Janeiro: Contra Capa/ Associação Brasileira de Antropologia.

Diehl, E. E., Langdon, E. J. e Dias-Scopel, R. P. (2012). Contribuição dos agentes indígenas de saúde na atenção diferenciada à saúde dos povos indígenas brasileiros. Cadernos de Saúde Pública 28(5), 819-831. 
FOIRN - Federação das Organizações Indígenas do Rio Negro. (2006) Saúde Indigena: FOIRN encerra convénio com FUNASA. Disponivel em: http://port. pravda.ru/cplp/brasil/01-1102006/13599-foirnsaudeindigena.

Ferreira, L. O. (2013). Medicinas Indigenas e as Politicas da Tradição: entre discursos oficiais e vozes indigenas. Rio de Janeiro: Fiocruz.

Follér, M.-L. (2004). Intermedicalidade: a zona de contato criada por povos indígenas e profissionais de saúde. Em Langdon e Garnelo (Orgs.) Saúde dos Povos Indígenas - reflexões sobre a antropologia participativa (pp. 129-148). Rio de Janeiro: Contra Capa/Associação Brasileira de Antropologia.

Garnelo, L. (2012). Política de Saúde Indígena no Brasil: notas sobre as tendências atuais do processo de implantação do subsistema de atenção à saúde. Em Garnelo e Pontes (Orgs.) Saúde Indigena: uma introdução ao tema (pp. 18-59). Brasília: MEC-SECADI/UNICEF.

Garnelo, L. e Sampaio, S. (2003). Bases sócio-culturais do controle social em saúde indígena. Problemas e questões na Região Norte do Brasil. Cad. Saúde Pública 19(1), 311-317.

Garnelo, L. e Sampaio, S. (2005). Organizações indigenas e distritalização sanitária: os riscos de "fazer ver" e "fazer crer" nas políticas de saúde. Cad. Saúde Pública 21(4),1217-1223.

Ghiggi Jr., A. e Langdon, E. J. (2013). Controle Social como Autoatenção: estratégias Kaingang diante do abuso de bebidas alcoólicas. Em Ponte de Souza (Org.) Processos de Alcoolização Indigena no Brasil: Perspectivas Plurais (pp. 159-178). Rio de Janeiro: Fiocruz.

IBGE - Instituto Brasileiro de Geografia e Estatística (2010a) Tabela 1.14 Pessoas indigenas, por sexo, segundo o tronco linguístico, a família linguística e a etnia ou povo - Brasil-2010. Disponivel em: ftp://ftp.ibge.gov.br/Censos/Censo_ Demografico_2010/Caracteristicas_Gerais_dos_Indigenas/pdf/tab_1_14.pdf.

IBGE - Instituto Brasileiro de Geografia e Estatística (2010b) Tabela 3.1 Pessoas residentes em terras indigenas, por condição de indigena, segundo as Unidades da Federação e as terras indigenas - Brasil - 2010. Disponivel 
em: ftp://ftp.ibge.gov.br/Censos/Censo_Demografico_2010/Caracteristicas_ Gerais_dos_Indigenas/pdf/tab_3_01.pdf.

Langdon, E. J. (2013). Medicina tradicional: reflexões antropológicas sobre atenção diferenciada. Em Haverroth (Org.). Etnobiologia e Saúde dos Povos Indigenas. (pp. 15-35). Recife/Florianópolis: NUPEEA/INCT Brasil Plural.

Langdon, E. J., Diehl, E. E., Wiik, F. B. e Dias-Scopel, R. (2006). A participação dos agentes indígenas de saúde nos serviços de atenção à saúde: a experiência em Santa Catarina, Brasil. Cadernos de Saúde Pública 22(12), 2637-2646.

Langdon, E. J. e Diehl, E. E. (2007). Participação e Autonomia nos Espaços Interculturais de Saúde Indigena: reflexões a partir do sul do Brasil. Saúde Soc. 16(2), 19-36.

Langdon, E. J., Diehl, E. E. e Dias-Scopel, R. P. (no prelo). O papel e a formação dos Agentes Indígenas de Saúde na atenção diferenciada à saúde aos povos indígenas brasileiros Em Teixeira e Garnelo (Orgs.) Saúde Indigena em Perspectiva: explorando suas matrizes históricas e ideológicas. Rio de Janeiro: Fiocruz.

Machado, F. A. (1986). Participação social em saúde. Relatório da VIII Conferência Nacional de Saúde (pp. 299-305). Brasília: Ministério da Saúde.

Magalhães, E. D. (2001). O Estado e a saúde indígena: a experiência do Distrito Sanitário Yanomami. Dissertação de Mestrado (Política Social). Brasília, Universidade de Brasília.

Menéndez, E. (2010). Participación social en salud como realidad técnica y como imaginario social privado. Cuadernos médico sociales 73, 5-22.

Pontes, A. L., Stauffer, A. e Garnelo, L. (2012). Profissionalização indígena no campo da saúde: desafios para a formação técnica de Agentes Indígenas de Saúde. Em Garnelo e Pontes (Orgs.) Saúde Indigena: uma introdução ao tema. (pp. 265-288). Brasília: MEC-SECADI/UNICEF.

Portal Brasil (2014). Comunidades indigenas terão $R \$ 1$ bilhão em serviços básicos. Disponível em: http://www.brasil.gov.br/saude/2013/10/ comunidades-indigenas-terao-r-1-bilhao-em-servicos-basicos. 
Shankland, A. e Athias, R. (2007). Decentralisation and difference: indigenous peoples and health system reform in the Brazilian Amazon. IDS Bulletin 38(1), 1-23.

Silva, C. T. da (2012). Indigenismo como ideologia e prática de dominação. Apontamentos teóricos para uma etnografia do indigenismo latino-americano em perspectiva comparada. Latin American Research Review 47(1),16-34.

\section{Cómo citar este artículo}

Diehl, E. E. (2015). Transformações na Atenção à Saúde Indígena: Tensões e Negociações em um Contexto Indigena Brasileiro. Universitas Humanística, 80, 213-236. http://dx.doi.org/10.11144/Javeriana.UH80.tasi 